\title{
Tre registre over Grundtvigs gendigtninger af Brorson
}

\author{
Sune Auken og Johan Damsgaard
}




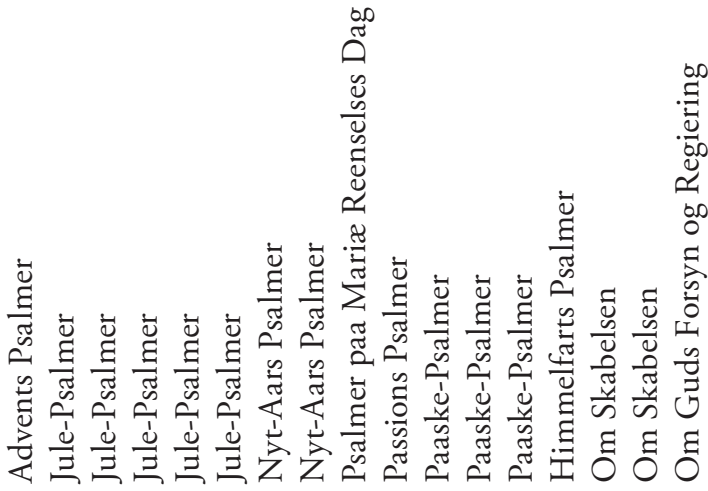

$\dot{0}$
$\dot{0}$

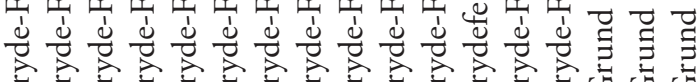

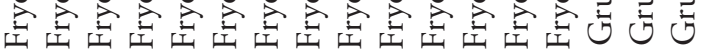

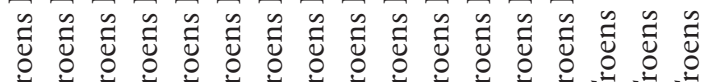

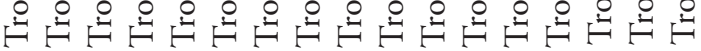

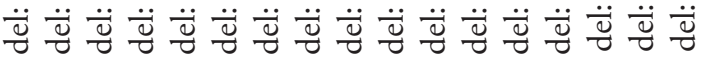

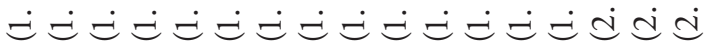

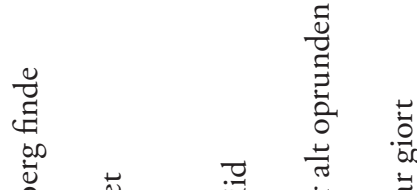

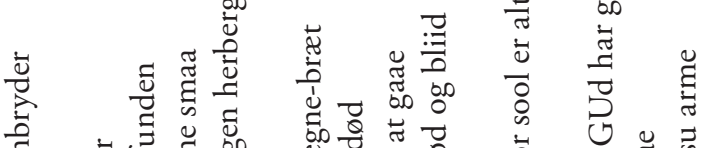

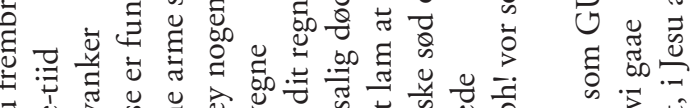

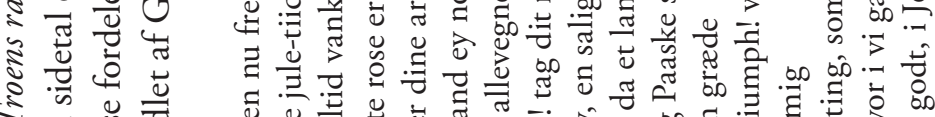
$\star \varepsilon$ च च

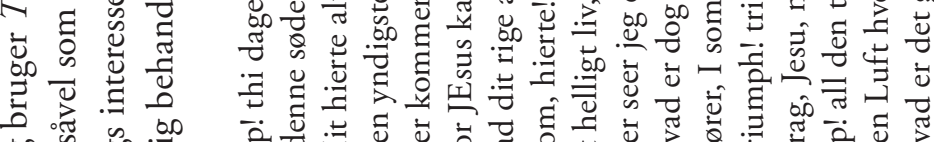

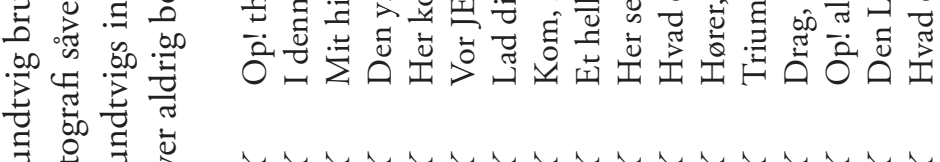
苞苟苞

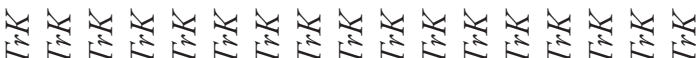




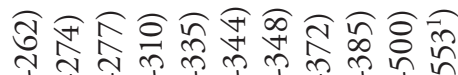

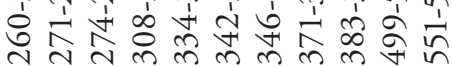

$\dot{s} \dot{s} \dot{s} \dot{s} \dot{s} \dot{s} \dot{s} \dot{s} \dot{s}$

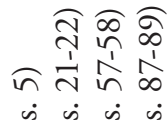

芯

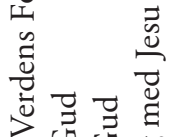

6. 0.0

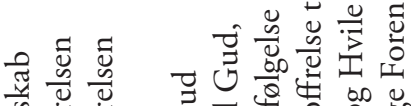

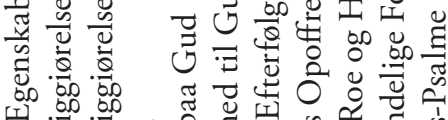

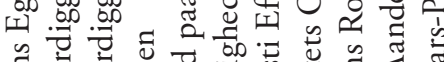

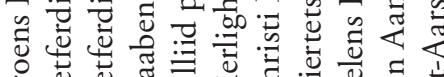

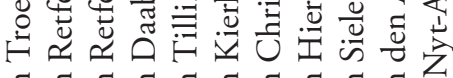
ถั

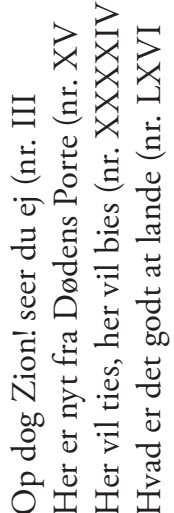

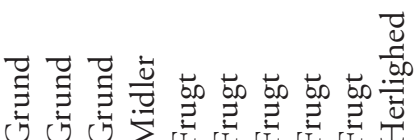

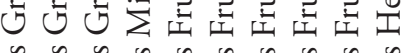

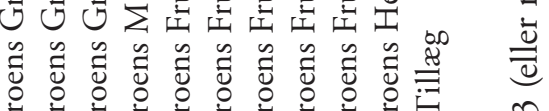

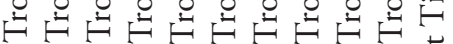

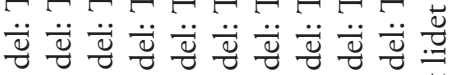

蓠

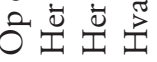




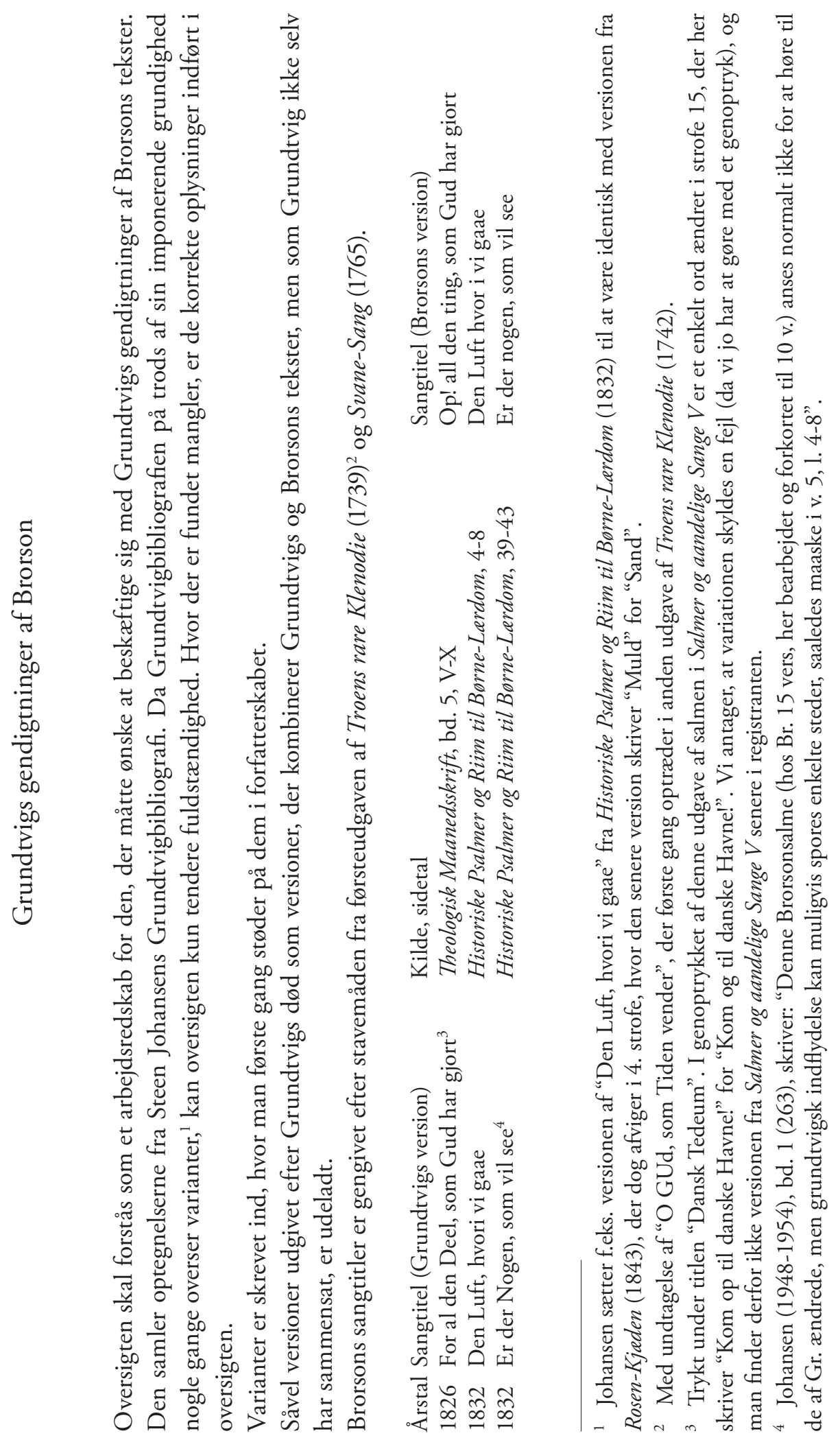




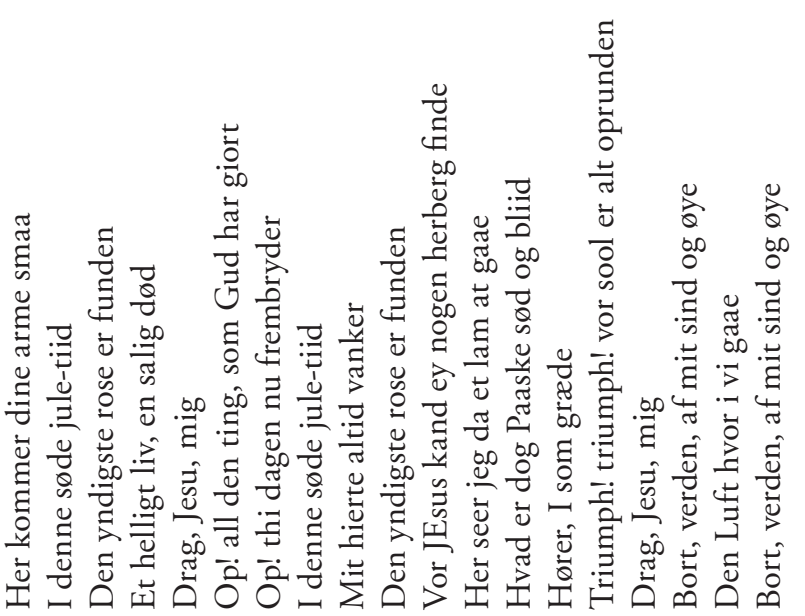

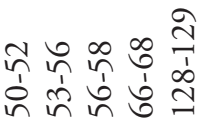

ई

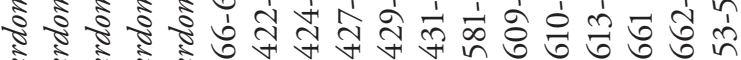

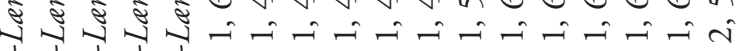

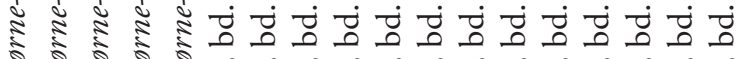

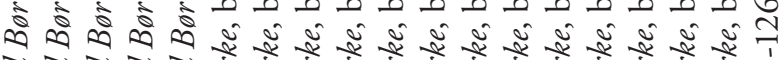

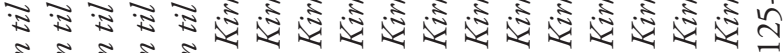

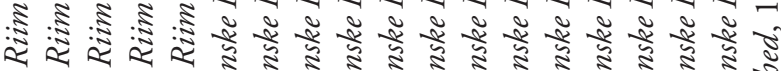

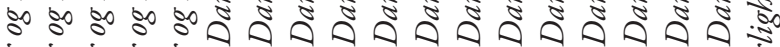

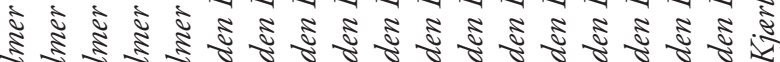

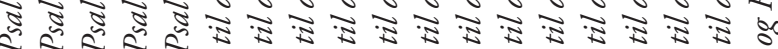

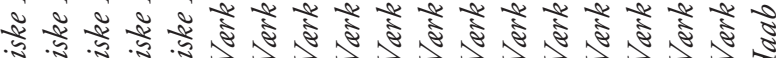
(.

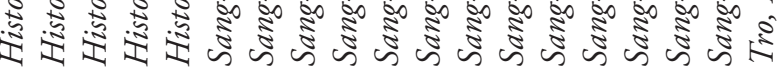

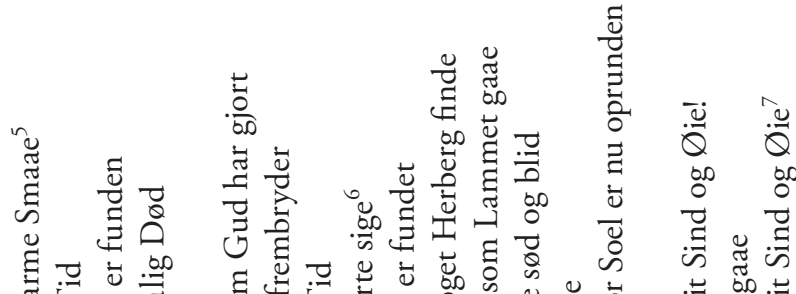

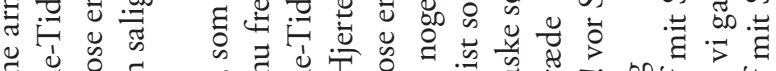

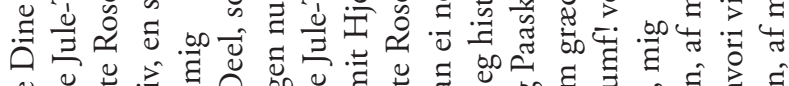

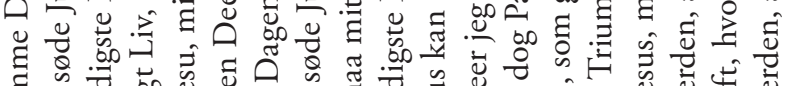

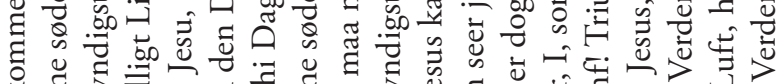

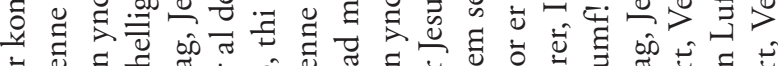

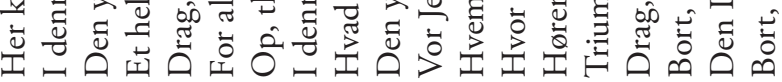

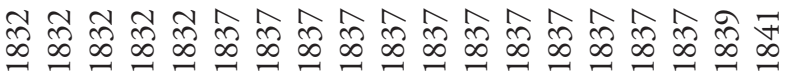

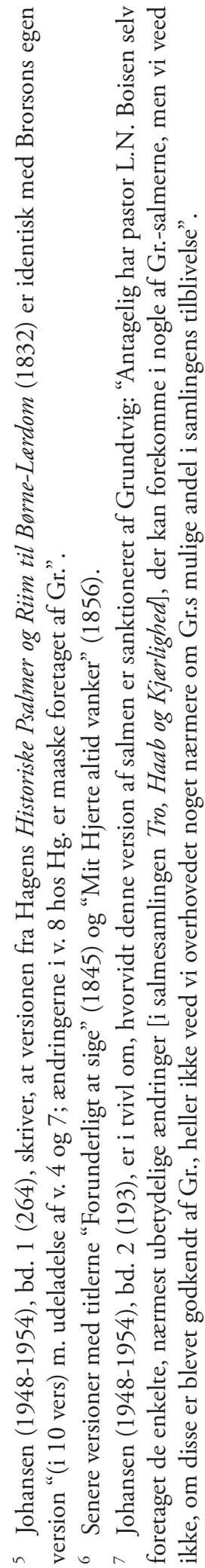


$\frac{.}{60}$

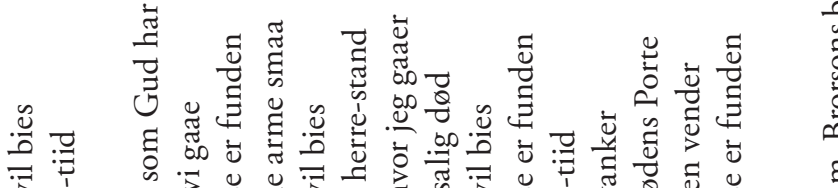

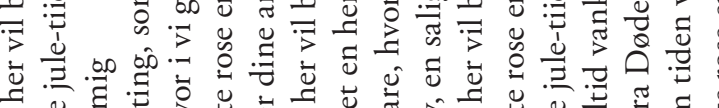

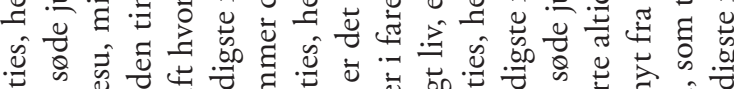

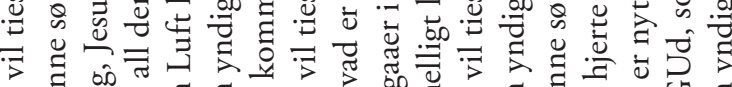

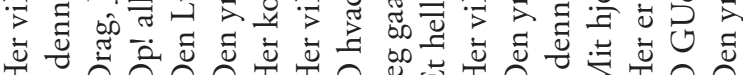

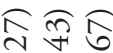

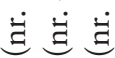

ம்

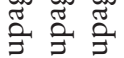

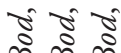

$\infty \infty$

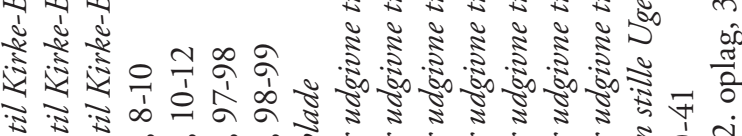

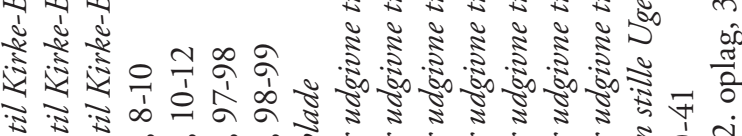

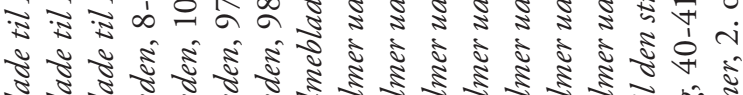
का รั

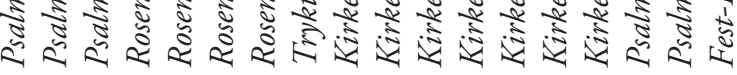

$\frac{5}{60}$

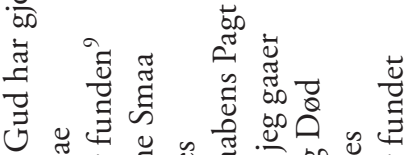

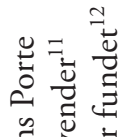

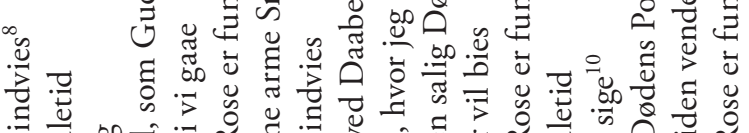

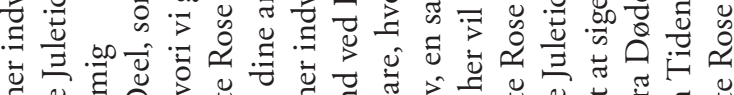
呵

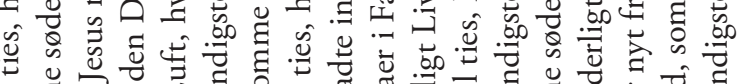

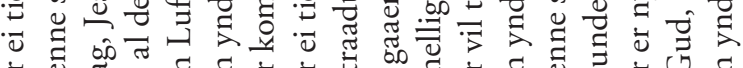

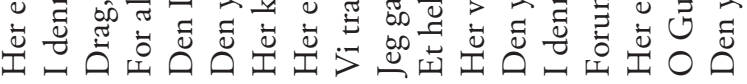

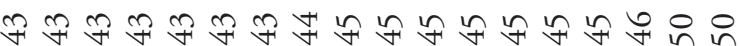

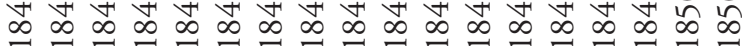

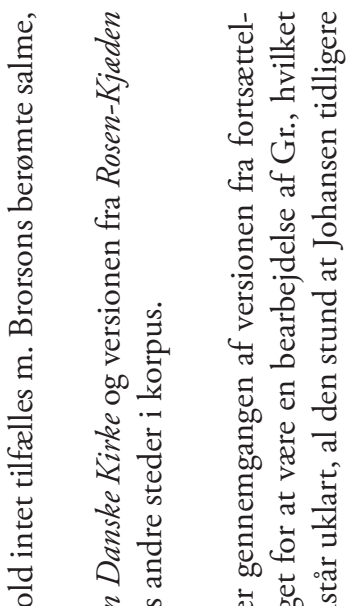

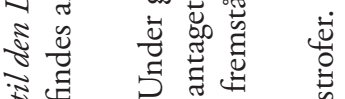

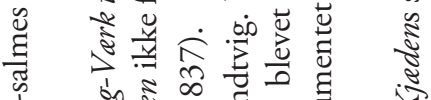

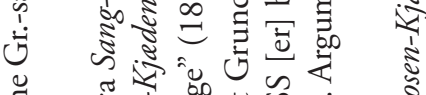

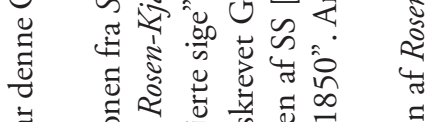

芩.

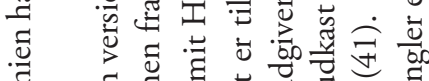

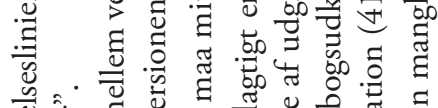

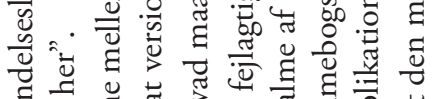

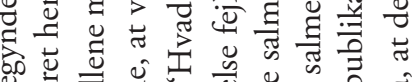

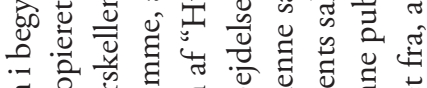

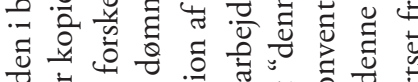

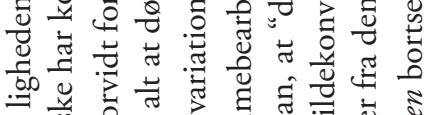

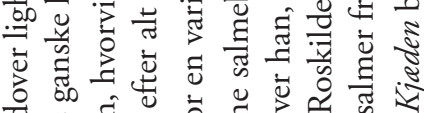

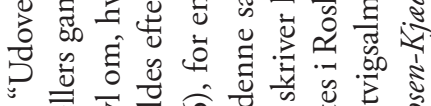
记

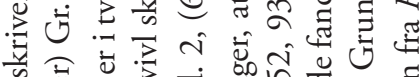

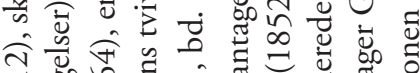

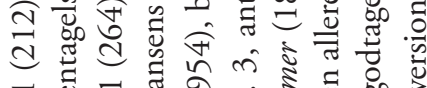

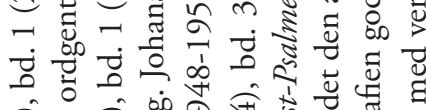

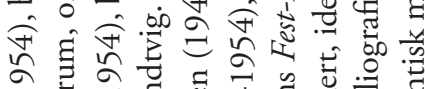
के

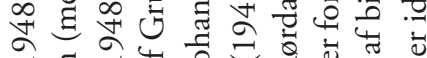

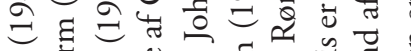

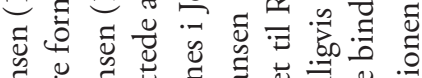

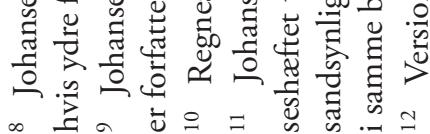




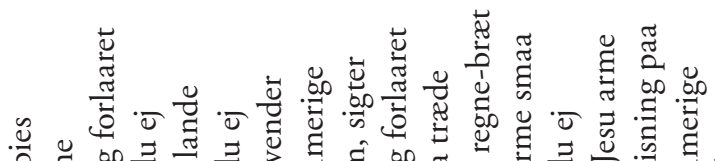

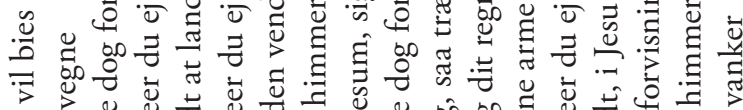

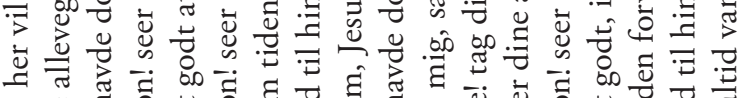
s.

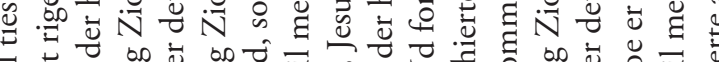
$\bar{\nabla}$

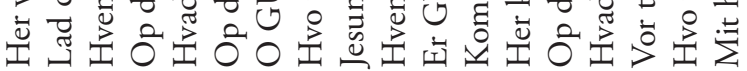

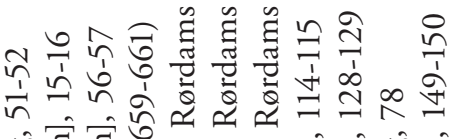

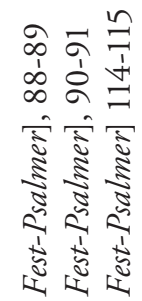

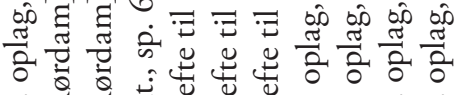

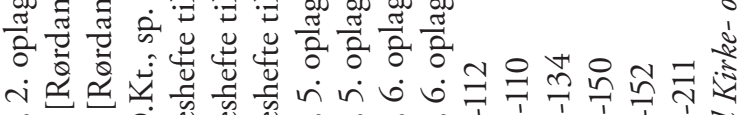

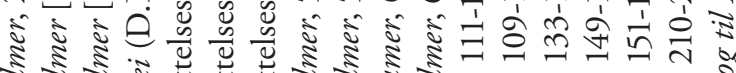

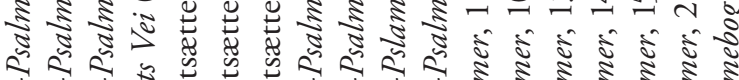

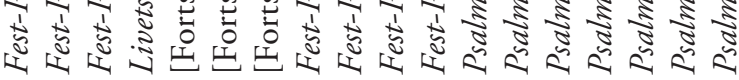

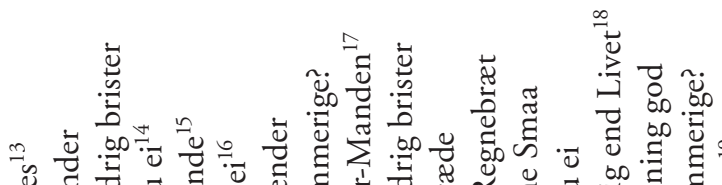

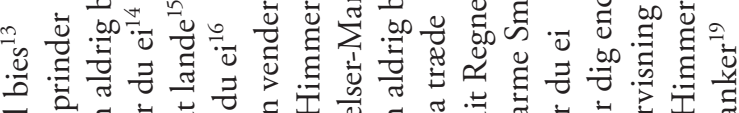

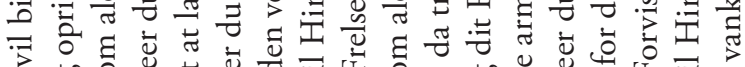

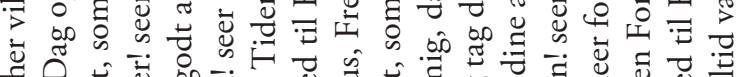

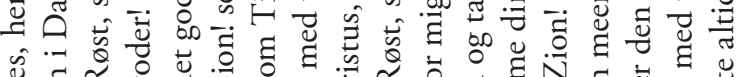

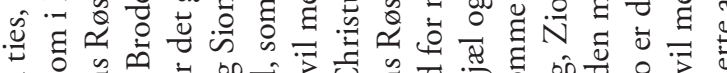

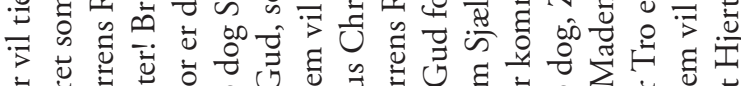

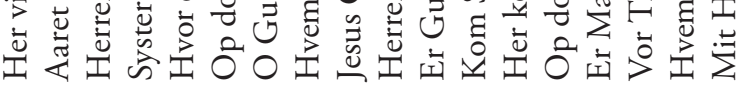

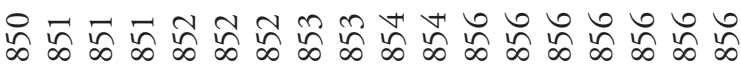

$\stackrel{-1}{2}$

รั

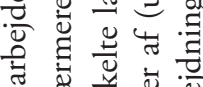

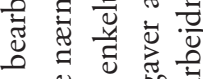

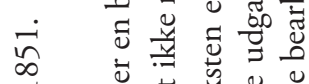

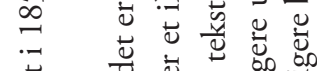

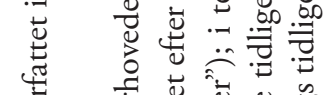

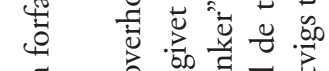

可

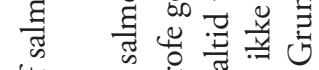

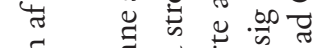

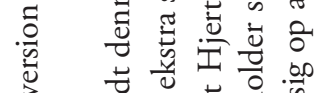

品

$5 \quad$.

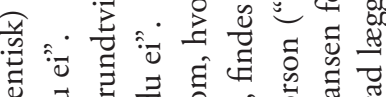

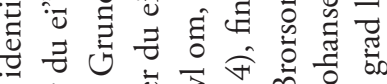

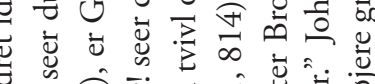

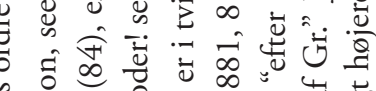

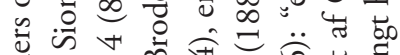
\%

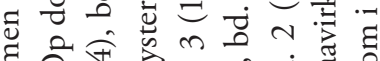

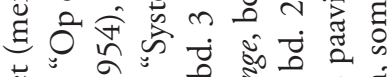

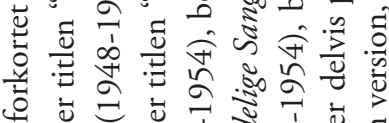
क्षै ป 与ै

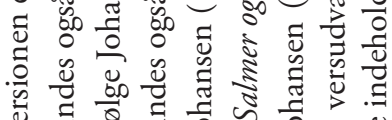

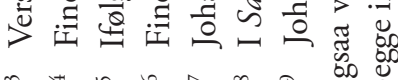




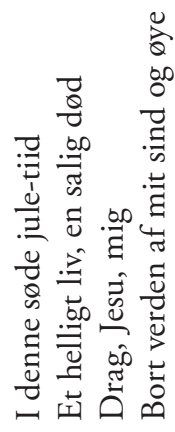

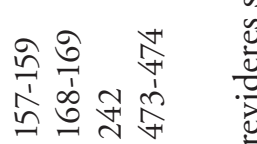

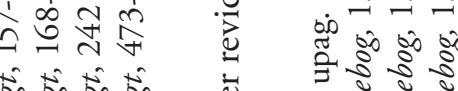

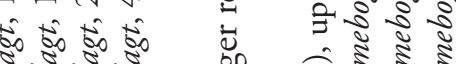

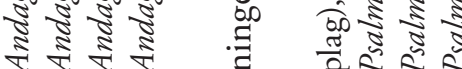

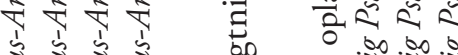

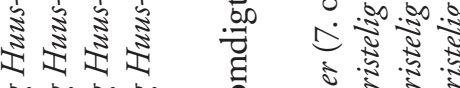

8000000 है है है

ฉัँ

这运运这

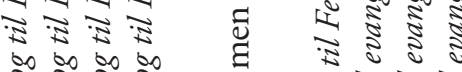

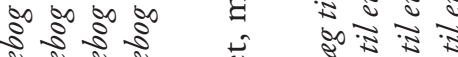

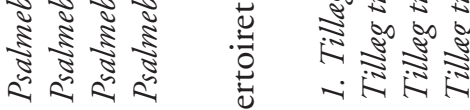

อัป

ค.

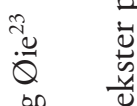

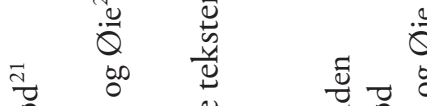

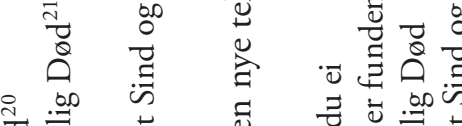

苛

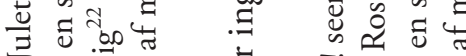

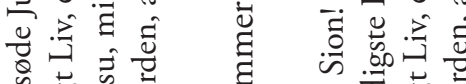

क.

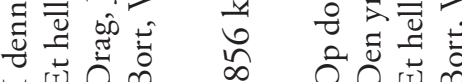

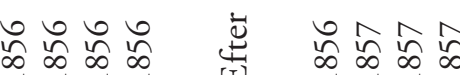

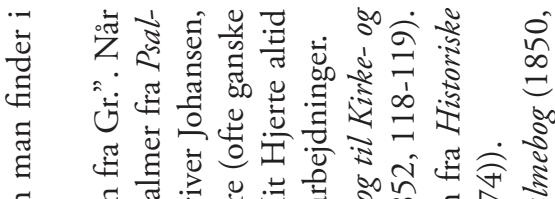

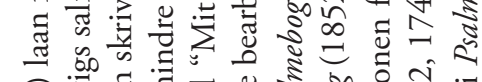

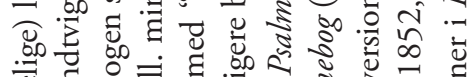

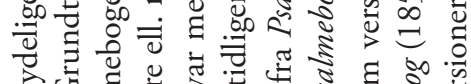

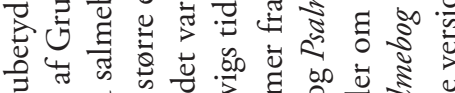
tँ 2.

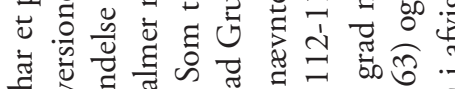

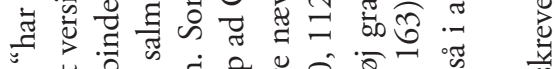
वี प्र

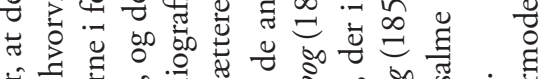

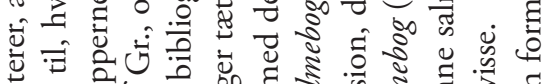

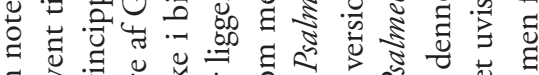

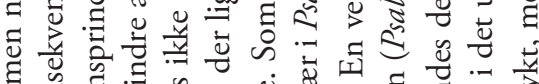
\&

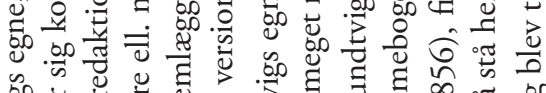
ब.

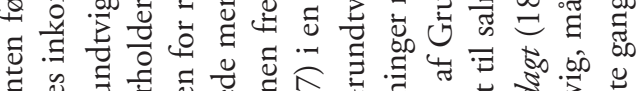

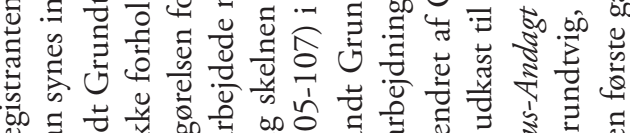

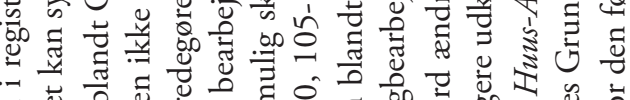

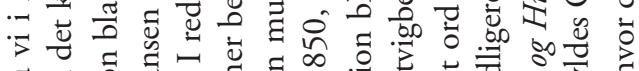

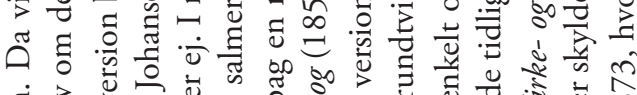

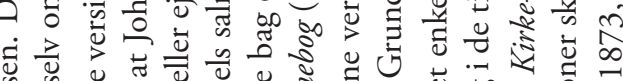
बं

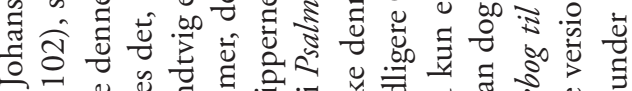

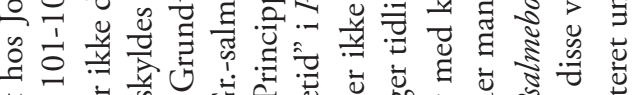

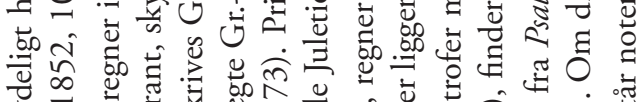

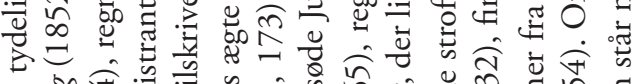

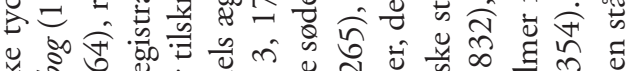

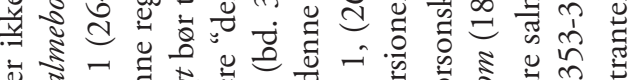

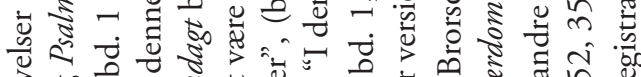
क人 ठ઼

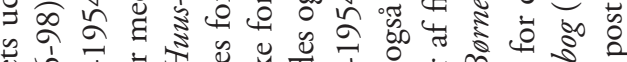

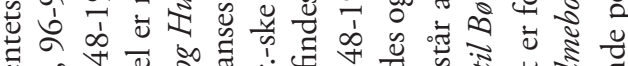

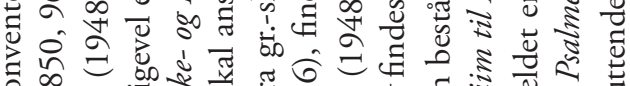

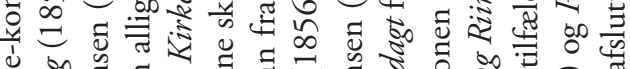

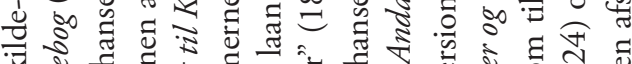

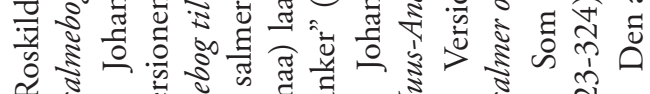




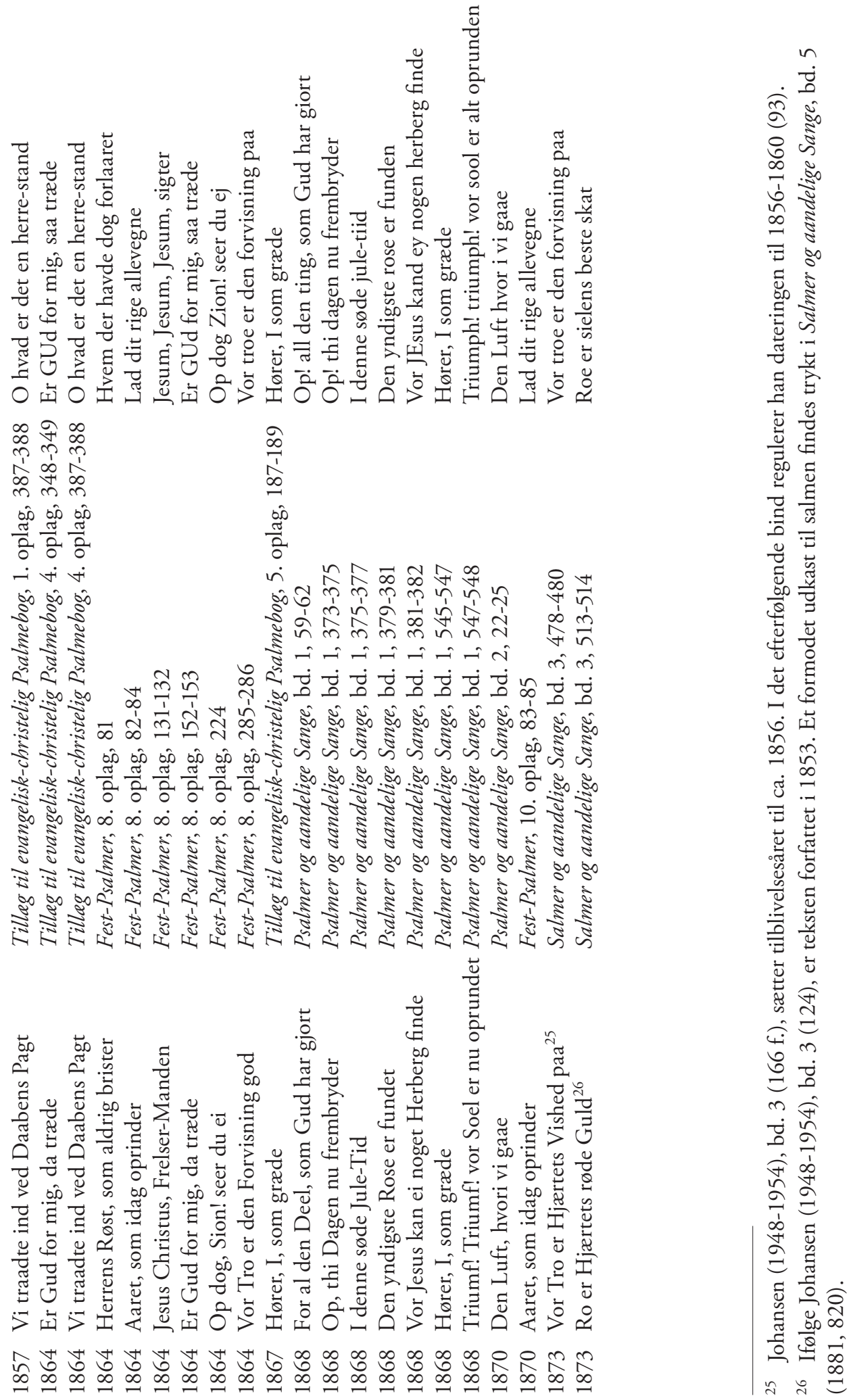



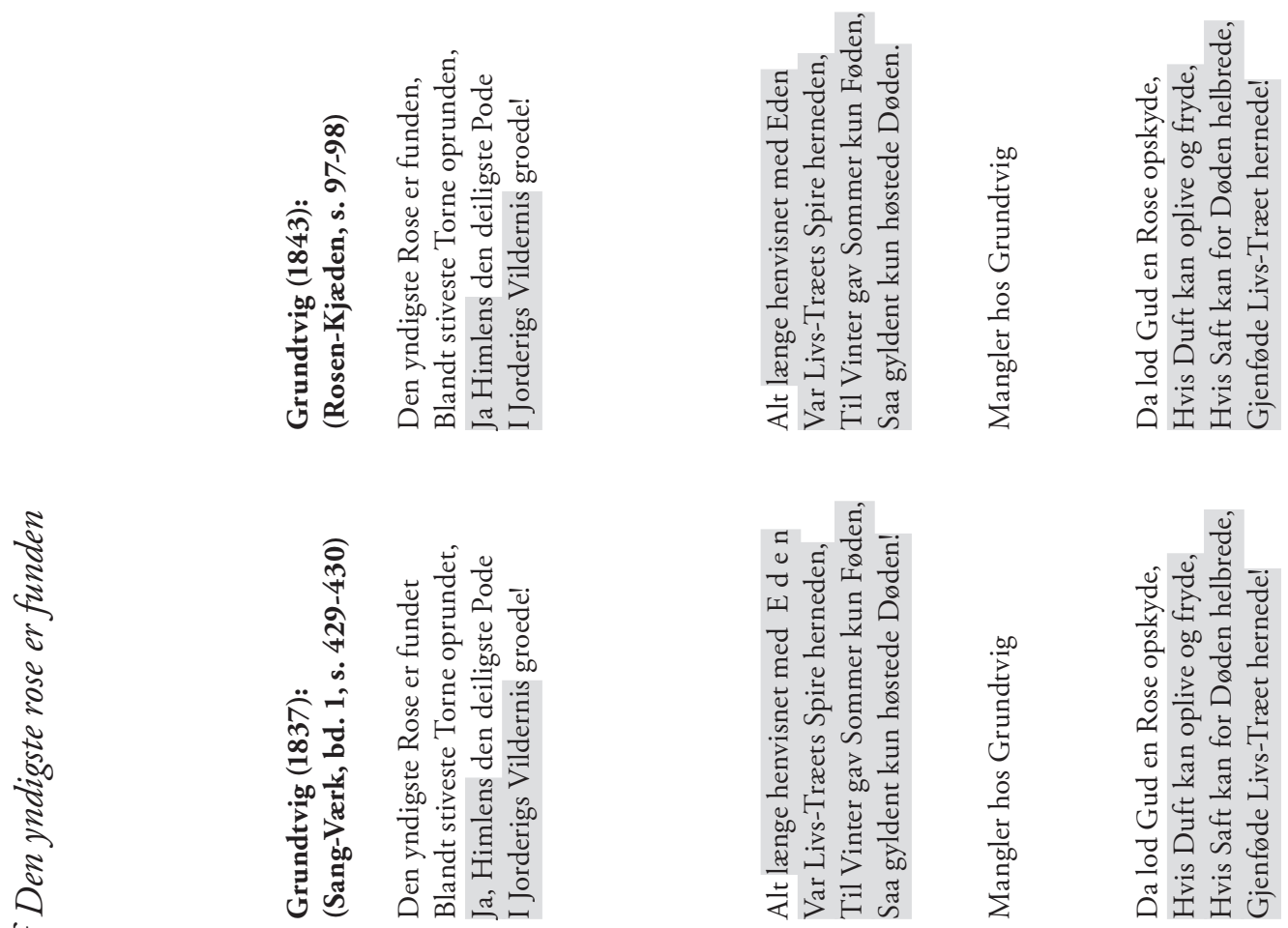

茨

苛

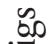

莺
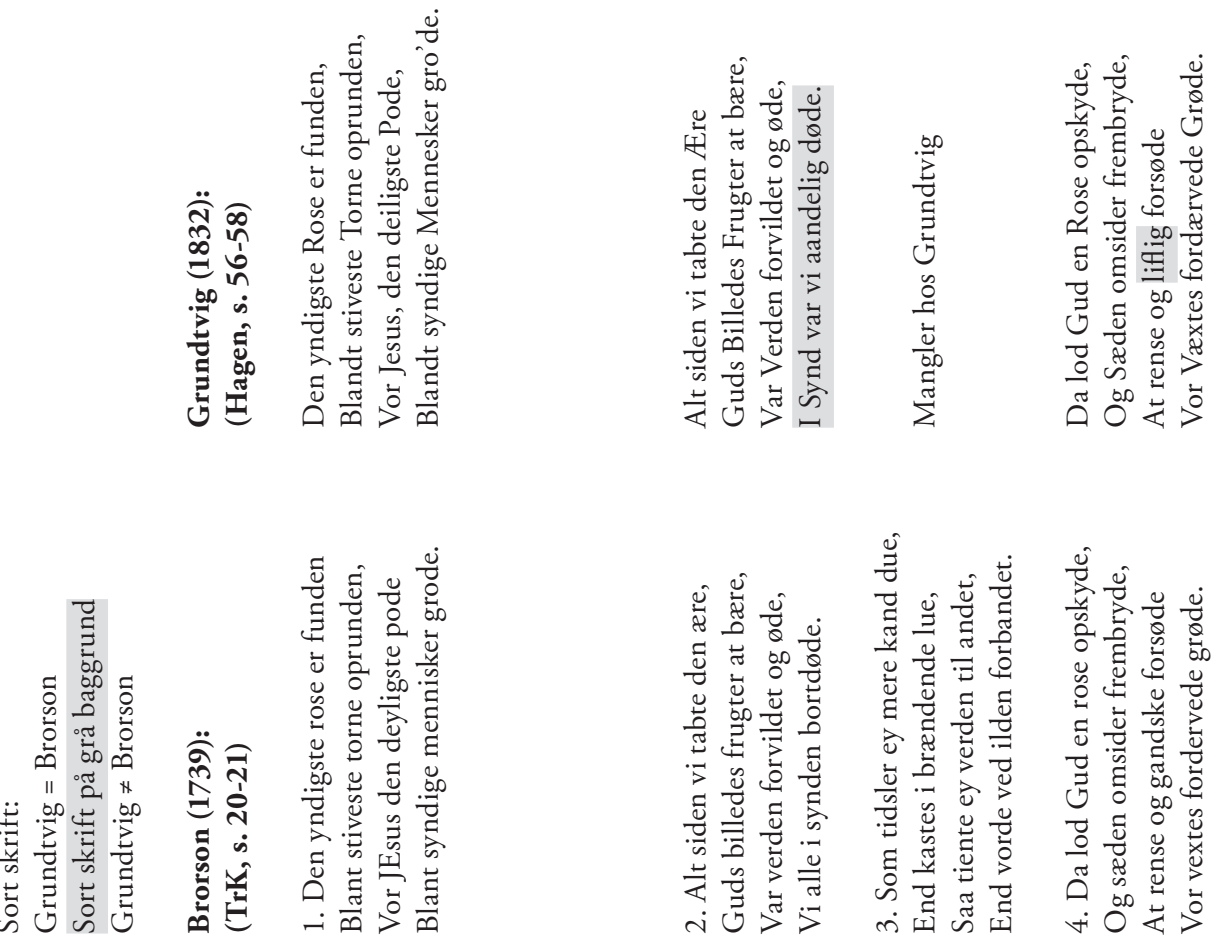

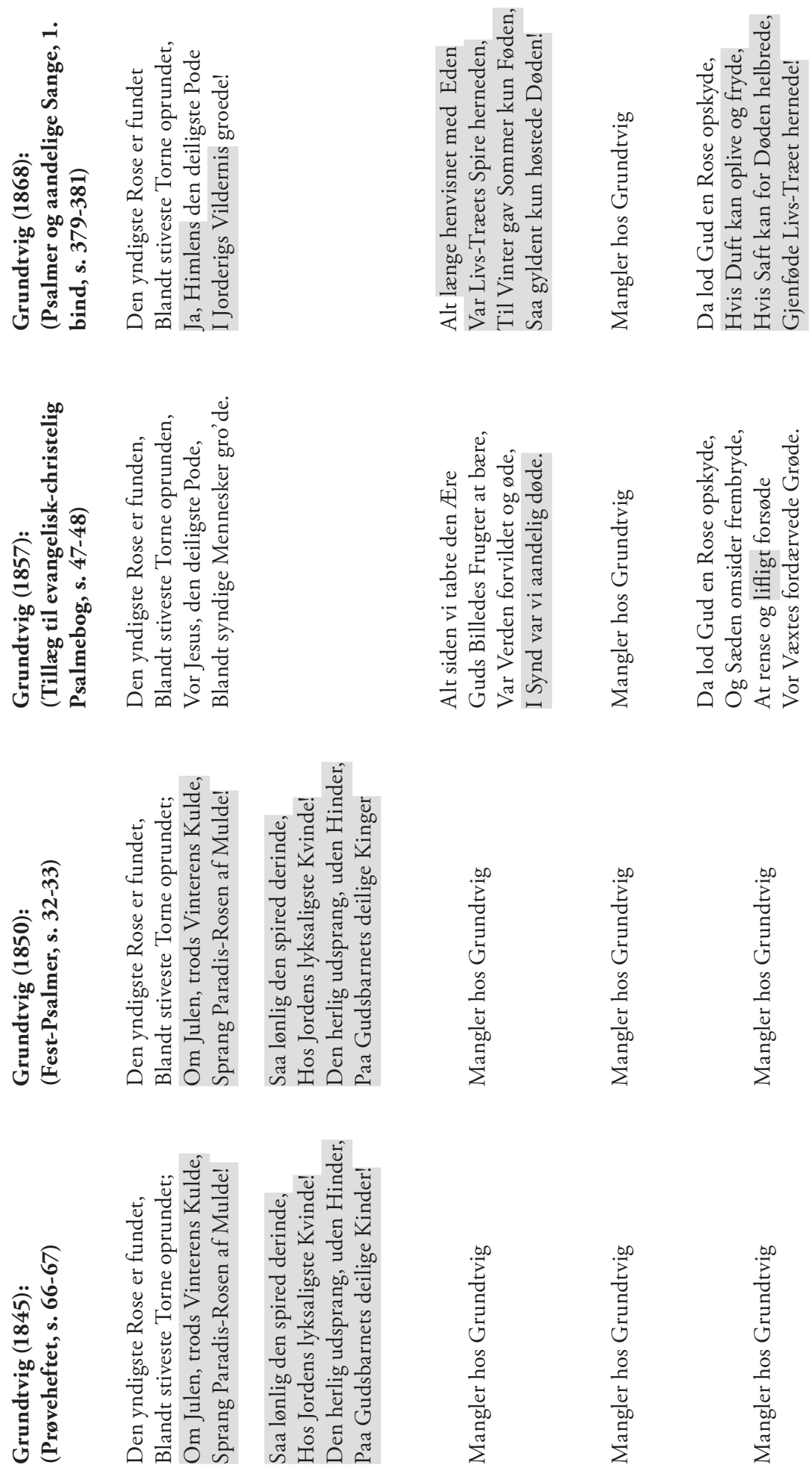

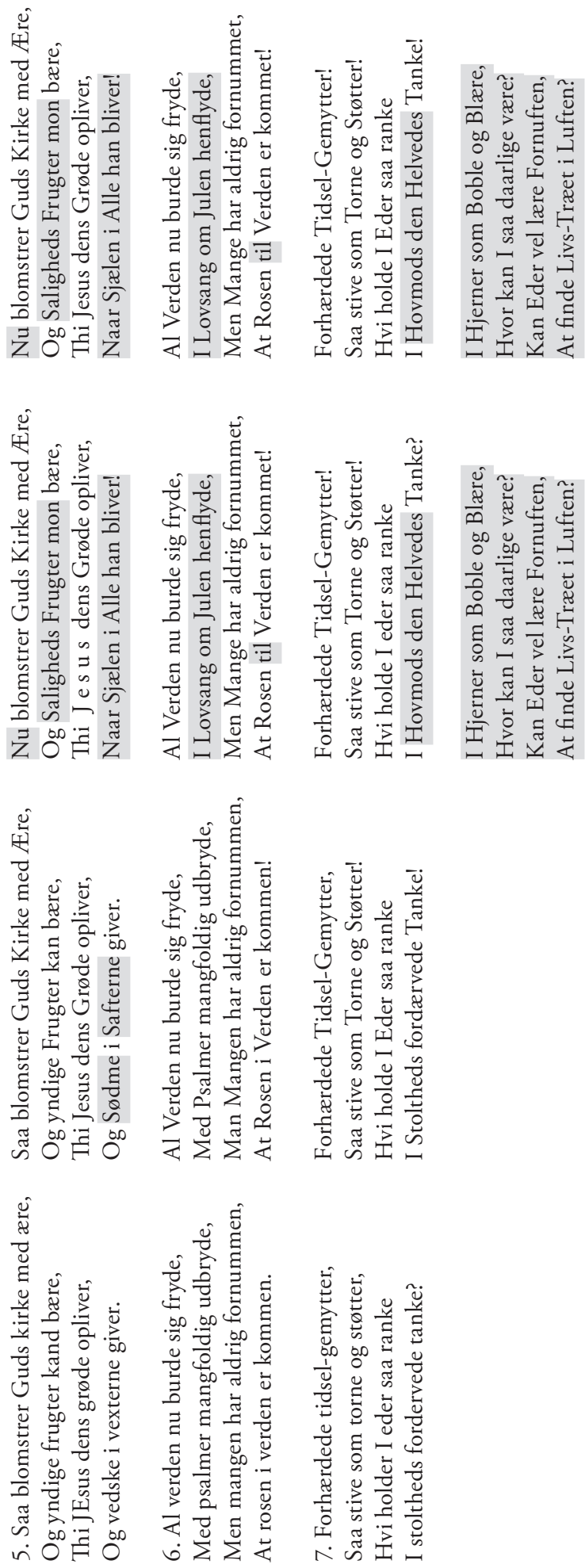

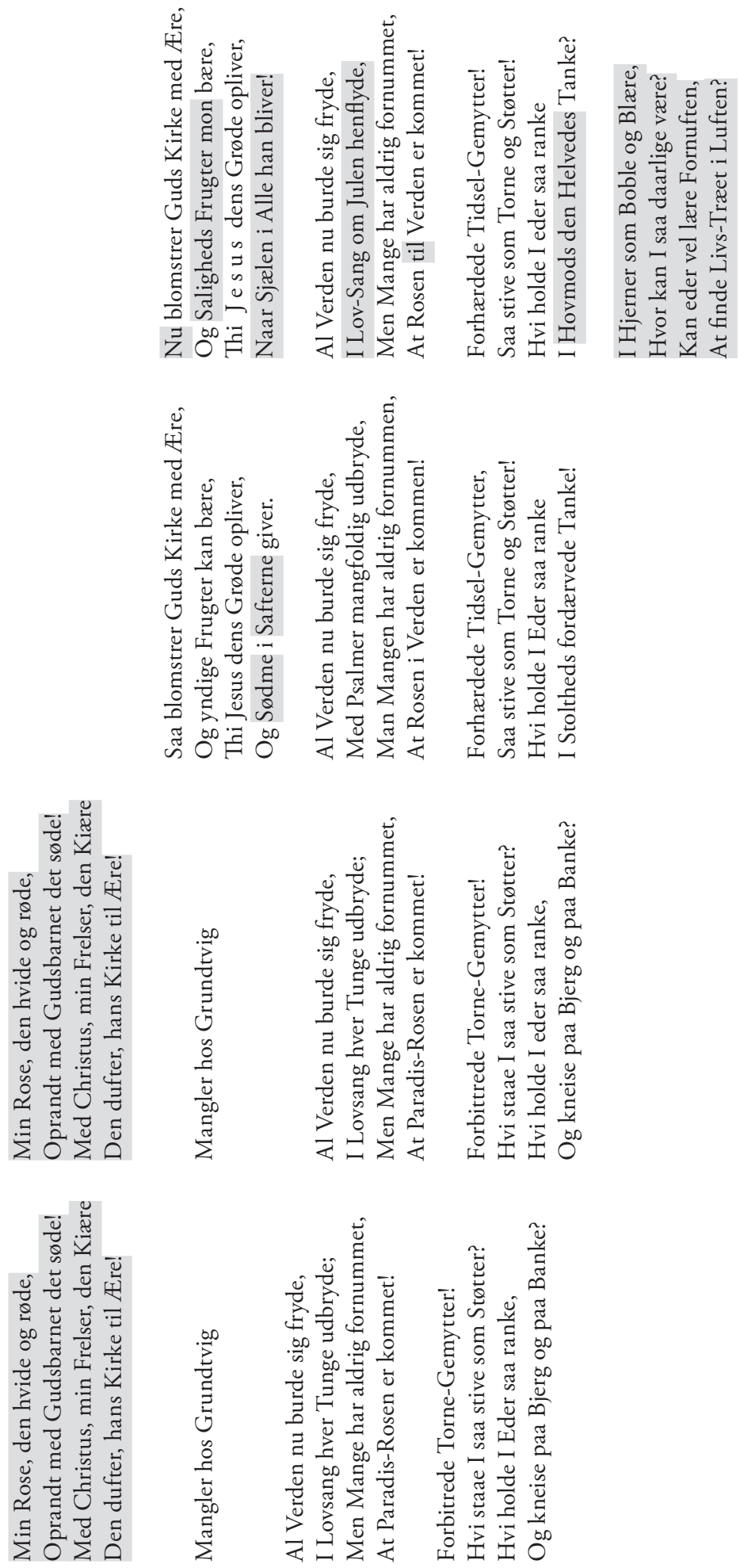

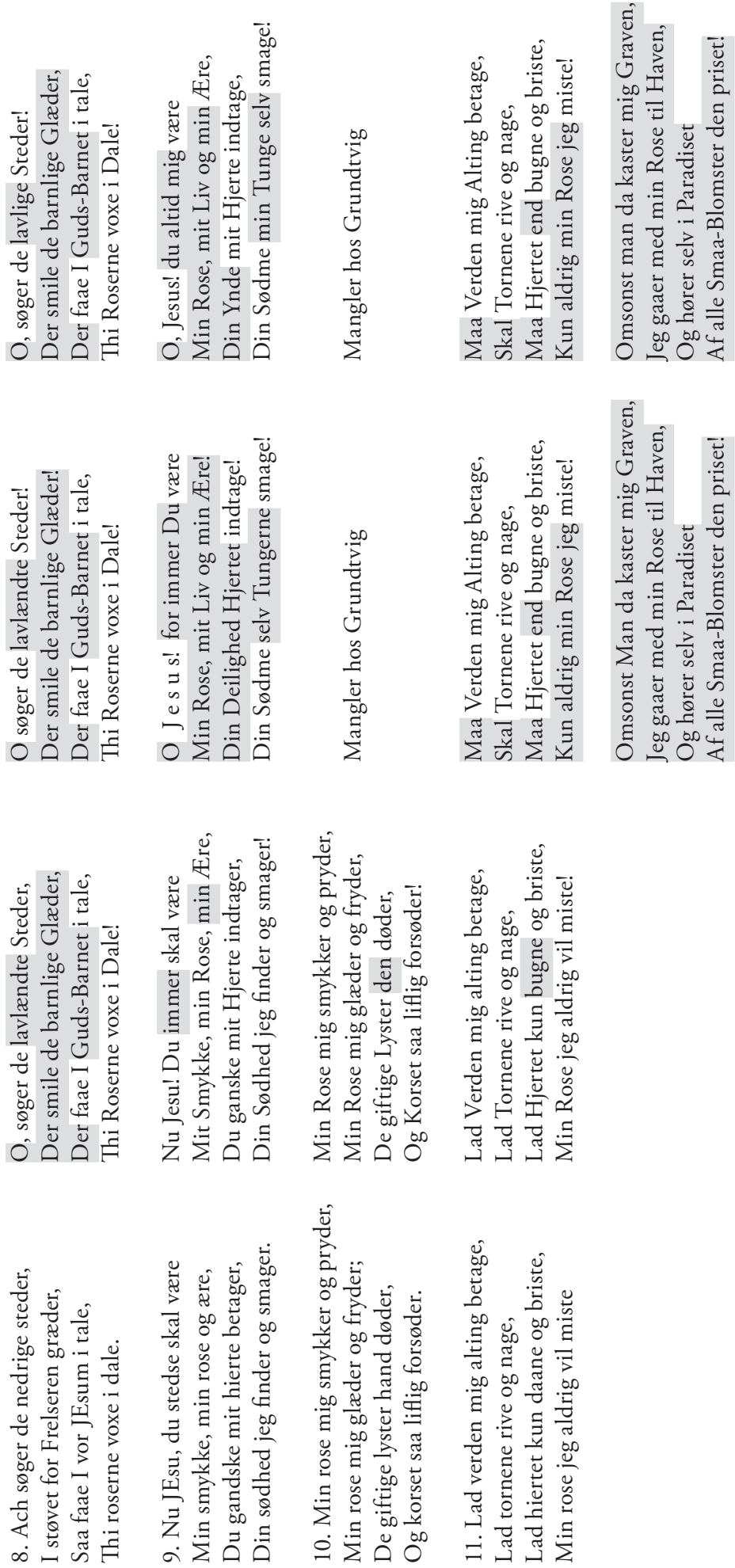


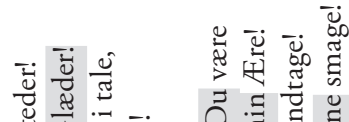
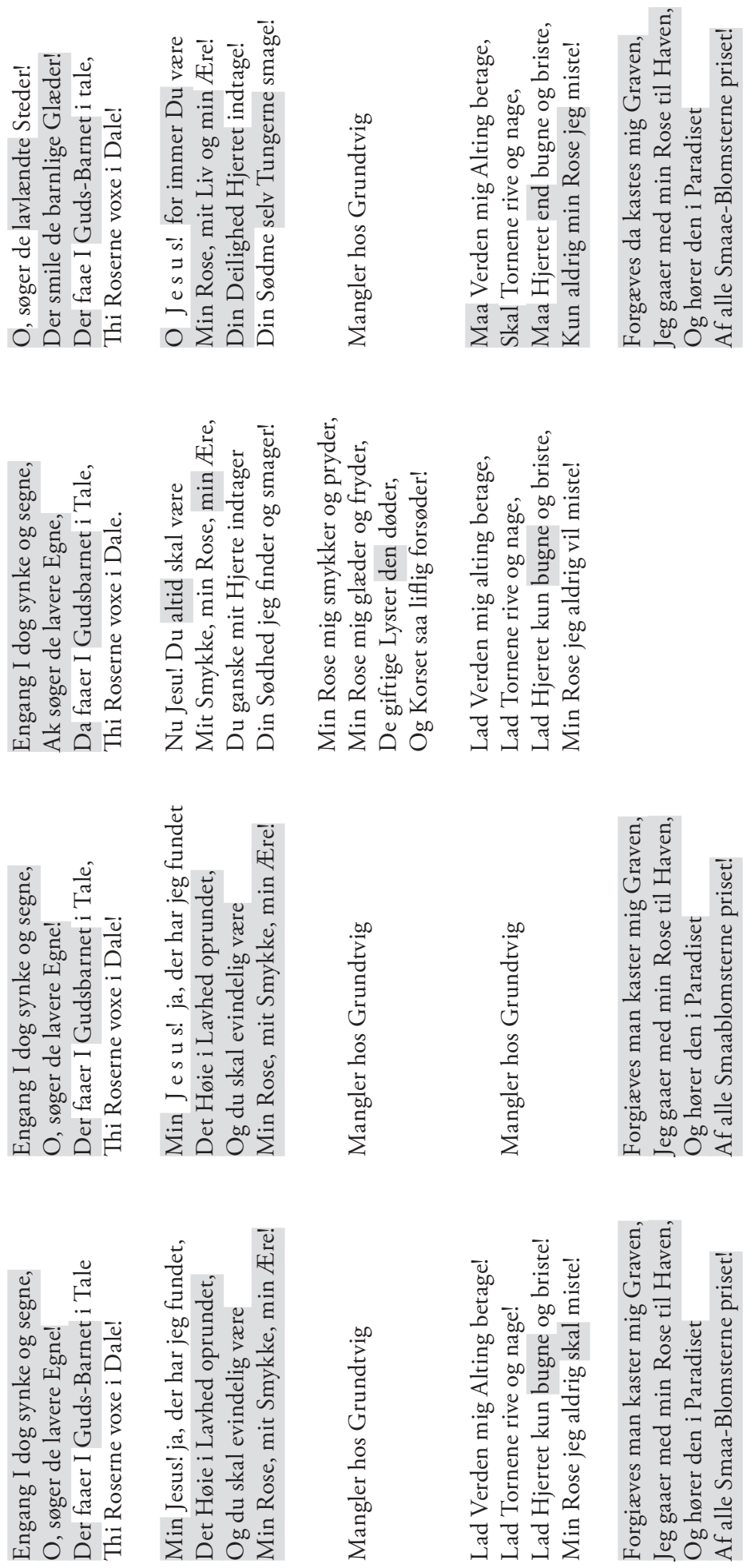